\title{
Núñez Cortés, Juan Antonio (coord.). Escritura académica: de la teoría a la práctica. Madrid: Ediciones Pirámide (Grupo Anaya), 2016, pp. 157.
}

\author{
David Sánchez-Jiménez \\ CUNY New York City College of Technology \\ dsanchezjimenez@citytech.cuny.edu \\ doi.org/10.17533/udea.lyl.n75a12
}

$\mathrm{E}^{\mathrm{n}}$ n las últimas décadas se ha venido impulsando en lengua española una nueva corriente revisionista que trata de acercar las prácticas de escritura a la universidad siguiendo el modelo anglosajón que supuso una auténtica revolución en este campo en la segunda mitad del pasado siglo (véanse Carlino, 2005; Castelló, 2014). Fruto de tal impulso, numerosas publicaciones han visto la luz en el mercado editorial. Escritura Académica. De la teoría a la práctica es un pequeño manual, modesto por su tamaño y por la selección temática de sus contenidos, en el que sus autores ponen el énfasis en algunos de los temas centrales de la escritura académica, como son la corrección gramatical, la ortografía, la puntuación, la estructura de los géneros discursivos y de los tipos de texto más relevantes utilizados en el contexto académico, los cuales requieren el refuerzo de una mayor exposición en el nivel educativo universitario. Esto se hace en el volumen que reseñamos mediante una ordenada y clara explicación de los contenidos teóricos, trabajados mediante atractivos ejercicios y actividades específicamente diseñadas para practicar las cuestiones conceptuales planteadas en el texto.

El libro se inicia con un apartado introductorio firmado por el coordinador del volumen, Juan Antonio Núñez Cortés, quien a su vez es también el autor del primer capítulo, en el que se expone la situación y el uso actual de la escritura en el currículo universitario. La obra avanza con un segundo capítulo, en el cual se realiza un repaso general por las cuestiones gramaticales que con más frecuencia afectan la corrección de los textos en este nivel de enseñanza. El tercer capítulo se centra en la diversidad de géneros discursivos de escritura utilizados convencionalmente en la universidad, fijando su análisis sobre la reseña académica, el resumen, la monografía y el examen escrito. Los dos últimos apartados definen los tipos de texto de la exposición y la argumentación e incorporan tanto estrategias como ejercicios expresamente diseñados para comprender y facilitar su redacción. 
Ya desde la introducción, Juan Antonio Núñez Cortés advierte del contexto de actuación y del propósito que aúna los distintos capítulos. Este título surge motivado por la necesidad de adaptarse a los cambios acaecidos en la sociedad en los últimos años, los cuales han introducido inevitablemente modificaciones en el modo en que funciona la universidad, a la cual se han incorporado de forma natural las nuevas tecnologías. De igual modo, en las últimas décadas se ha experimentado un mayor movimiento e intercambio entre las universidades de distintos países que ha promovido su internacionalización. Estos factores no pueden pasar desapercibidos para los miembros de tales instituciones, quienes deben hacer un esfuerzo equivalente que responda a esta nueva realidad para adaptarse a los tiempos actuales. Desde la perspectiva del tema que vehicula el libro, el autor insiste en el desempeño que tiene la escritura académica para el aprendizaje en la enseñanza superior. Por ello, Juan Antonio Núñez Cortés define los conceptos fundamentales de comunidad discursiva y de la función epistémica de la escritura, con el fin de aproximarse a una mejor comprensión de las implicaciones que existen entre dicha destreza y el aprendizaje de contenidos en los estudios universitarios de grado en las distintas disciplinas. El autor no obvia las carencias con las que el estudiante llega a la universidad e insiste en la obligación pedagógica de los docentes de considerar las mejores medidas que permitan equipar al estudiante con estas herramientas imprescindibles de aprendizaje para explorar las distintas áreas de conocimiento de su disciplina.

En el capítulo primero, Juan Antonio Núñez Cortés define el término de alfabetización académica y pone de manifiesto la importancia de integrar las destrezas discursivas escritas en el currículo universitario, así como la necesidad de atender a la variedad disciplinar que caracteriza los géneros en función de las convenciones estipuladas por cada comunidad discursiva. También reflexiona sobre algunas cuestiones metodológicas relacionadas con la escritura, la cual es interpretada desde una perspectiva cognitiva. En este enfoque, la composición del texto se entiende como un proceso recurrente delimitado en distintas fases que se superponen de manera cíclica (planificación, textualización, revisión), lo cual obliga al estudiante a reflexionar, reestructurar y reescribir el texto de manera constante. Esta forma de entender la expresión escrita está emparentada con la función epistémica de la escritura antes mencionada, ya que en ella el escritor está sometido a un continuo esfuerzo reflexivo en cada paso de la redacción, lo que le permite reformular el conocimiento adquirido durante el proceso de composición. Por último, Juan Antonio Núñez Cortés repara en el acto comunicativo del texto, en el que prioriza las necesidades expresivas del emisor para hacer llegar su voz de una forma personal al lector en el diálogo que se establece con este a lo largo del escrito. Esta visión se opone a una interpretación más tradicionalista de la academia, la cual premia la redacción de textos objetivos 
e impersonales que tienden a diluir la voz del autor, al mismo tiempo que excluyen de este proceso la identidad del que escribe.

Luego, en el segundo capítulo, Marta García Cañete presenta de manera sintética y bien ordenada las principales reglas de acentuación, puntuación y corrección gramatical con las que debe familiarizarse el estudiante en el nivel superior. La descripción de los temas ortográficos ocupa un lugar central en el apartado, hecho que la autora justifica por la función facilitadora que implica la adopción de un código común para el establecimiento de la comunicación y, en el caso de la puntuación, para jerarquizar la información del escrito. Marta García Cañete hace también referencia a las convenciones ortográficas que operan por encima de la variabilidad lingüística encontrada en la geografía hispánica y recoge las reglas actualizadas de ortografía correspondientes a los cambios introducidos por la Real Academia Española de la Lengua en la edición de la Ortografía de 2010, como las de la acentuación de los pronombres demostrativos, la letra "o" utilizada entre números y el tratamiento del adverbio "solo".

Posteriormente, el capítulo tercero corre a cargo de Cecilia Muse y Darío Delicia Martínez, quienes comienzan justificando la elección de los géneros discursivos seleccionados para el análisis en esta sección. Se excluyen, por ejemplo, los de mayor complejidad y longitud - trabajados típicamente en el posgrado- para enfocarse en aquellos que resultan más útiles para el estudiante que inicia su carrera universitaria y que trata de integrarse mediante el dominio de una disciplina del conocimiento: la reseña académica, el resumen, la monografía y el examen escrito. Los autores no solo ofrecen una concisa y certera definición y descripción de los mismos, sino que también los diseccionan en sus partes constituyentes para mostrar al alumno el funcionamiento de su estructura, lo cual será de gran utilidad en su posterior elaboración de estos escritos, ya que se trata de textos generales que el estudiante de casi cualquier disciplina tendrá que acometer en muchos de los cursos estudiados durante su estancia en la universidad.

Ya terminando de exponer el contenido del libro objeto de esta reseña, el capítulo cuarto es de autoría de Cecilia Muse y María Victoria Fernández, mientras que el quinto fue compuesto por Jacqueline Giudice. Ambos capítulos presentan una estructura similar en el desarrollo del contenido. Dentro de estos apartados se exponen una serie de estrategias diseñadas específicamente para la comprensión y la construcción de los textos expositivos (Capítulo 4) y argumentativos (Capítulo 5), aunque se tiene en consideración tanto la flexibilidad estructural como la de los componentes que los integran. Dicho sea de paso, estos dos tipos textuales pueden yuxtaponerse dentro de un mismo género discursivo, ya que a diferencia de aquellos, los tipos de texto como la exposición y la argumentación, más allá de las características que los 
singularizan $-\mathrm{y}$ que se explican de forma pormenorizada en estos capítulos - no responden a estructuras tipificadas por las convenciones sociales (Sánchez-Jiménez, 2016). Entre las operaciones cognitivas y discursivas de los textos expositivos las autoras mencionan que es frecuente encontrar elementos como la reformulación, la definición, el ejemplo, la analogía, la cita de autoridad, la clasificación, los conectores de enfoque expositivo, ordenadores del discurso o los elementos focalizadores, mientras que en los argumentativos, Jacqueline Giudice subraya la preferencia de otros recursos y técnicas como la metáfora, la analogías, la definición, el entimema, el ejemplo, el uso de preguntas retóricas o el argumento por autoridad o las citas y alusiones en la argumentación. La experta también comenta que el lenguaje utilizado en dicho tipo de texto se caracteriza por una marcada subjetividad con la que se pretende enfatizar la presencia del autor en el texto, pues este se identifica e implica intensamente con el mensaje que transmite en el escrito. Tal comportamiento dista bastante de los textos expositivos, los cuales son construidos a partir de mecanismos léxicos y gramaticales, como las estrategias de desagentivación u otro tipo de técnicas objetivadoras similares.

Por otra parte, el libro reseñado incluye una excelente colección de contenidos relevantes para el lector interesado en guiar al estudiante universitario en la escritura académica. A pesar de la breve extensión de la obra, esta no renuncia a la exhaustividad para centrarse en aquellas cuestiones cardinales de esta materia, que resultarán altamente significativas para el alumnado de la enseñanza superior. Resulta interesante para dicho colectivo por la claridad de su exposición y por la vertiente práctica que aportan los ejercicios introducidos en la obra, los cuales ilustran todos los conceptos teóricos de manera sistemática, pero también para los docentes, quienes podrán usarlo como un recurso complementario en el aula con el fin de reforzar alguno de los aspectos concretos de la escritura académica que cada docente considere que sus discentes deben mejorar. Por último, el solucionario que se incluye al final del libro viene a completar la interacción que los autores establecen con el lector por medio de la disposición de los ejercicios para que el alumno tenga la posibilidad de contrastar sus hipótesis y subsanar sus errores.

Otro de los logros más relevantes del libro tiene que ver con la armonía con la que se integran los temas expuestos en los cinco capítulos, así como la coherencia interna en la estructura textual compartida que sirve para organizar adecuadamente los escritos. En este sentido, se ha de considerar también el amplio espectro geográfico representado por la distinta procedencia de los autores que coinciden en este volumen, lo que aporta una amplia perspectiva descriptivista sobre la variación dialectal en los asuntos lingüísticos tratados. No obstante, la diversidad ha sido canalizada en la adhesión a los estándares normativos del español, los cuales se han priorizado más allá de las convenciones académicas específicas de cada país o universidad. 
En resumen, podemos afirmar que se ha conseguido con creces el propósito que originaba la elaboración de esta obra: familiarizar al estudiante universitario con los aspectos fundamentales de la escritura académica, para cuyo fin, damos fe, estará más que preparado si sigue con atención las pautas ofrecidas en el libro.

\section{Referencias bibliográficas}

1. Carlino, P. (2005). Escribir, leer y aprender en la universidad. Una introducción a la alfabetización académica. Buenos Aires: Fondo de Cultura Económica.

2. Castelló, M. (2014). Los retos actuales de la alfabetización académica: estado de la cuestión y últimas investigaciones. En I. Ballano e I. Muñoz (coords.) Escribir en el contexto académico (pp. 153-176). Bilbao: Publicaciones de la Universidad de Deusto.

3. Real Academia Española (2010). Ortografía de la lengua española. Madrid: Espasa Calpe.

4. Sánchez-Jiménez, D. (2016). Revisión crítica del concepto de género en el discurso escrito y su aplicación didáctica a la enseñanza de las lenguas con propósitos específicos. Estudios de Lingüística Aplicada, 34(64), pp. 207-236. 